\title{
MÉTOdo DE RESOLUÇÃo DE PROBLEMAS NO ENSINO MÉDIO: UMA PROPOSTA INTERDISCIPLINAR ABORDANDO O TEMA AGROTÓXICOS
}

\author{
PROBLEM SOLVING METHOD IN HIGH SCHOOL: AN INTERDISCIPLINARY \\ PROPOSAL ADDRESSING PESTICIDES THEME
}

DOI: http://dx.doi.org/10.23926/RPD.2526-2149.2018.v3.n2.p643-664.id265

\section{Daniel das Chagas de Azevedo Ribeiro Mestre em Educação Química (UFRGS). Doutorando em Educação em Ciências (UFRGS). professordanielufrgs@hotma il.com}

\section{Camila Greff Passos \\ Doutora em Educação \\ Química (UFRGS). \\ Professora Adjunta \\ (UFRGS). \\ camila.passos@ufrgs.br}

\section{Tania Denise Miskinis \\ Salgado}

Doutora em Ciências

(UFRGS).

Professora Titular (UFRGS). tania.salgado@ufrgs.br
Resumo: Este artigo apresenta a análise de uma sequência pedagógica na qual se utilizou a metodologia de Resolução de Problemas (RP) no Ensino Médio. A pesquisa visa à averiguação das formas de contribuição da sequência didática efetuada para a aprendizagem de conteúdos conceituais, procedimentais e atitudinais pertinentes às questões ambientais que os Agrotóxicos podem ocasionar. A investigação teve como sujeitos 35 alunos do $3^{\circ}$ ano do Ensino Médio de uma escola pública estadual da cidade de Porto Alegre/RS. Com o intuito de coletarmos os dados, foram utilizados o Diário de Campo dos pesquisadores, a produção escrita dos estudantes e a gravação do áudio da aula em que os educandos experienciaram a RP. A experiência realizada propiciou o incremento dos conteúdos conceituais, procedimentais e atitudinais relativos aos conhecimentos científicos abordados e aos problemas ambientais pertinentes aos Agrotóxicos.

Palavras-chave: Resolução de Problemas. Ensino Médio. Educação Ambiental. Agrotóxicos.

\begin{abstract}
This article presents the analysis of an pedagogical sequence in which Problem Solving methodology (RP) was used in High School. The research aims to investigate the contribution of the didactic sequence carried out to the learning of conceptual, procedural and attitudinal contents pertinent to the environmental issues that Pesticides can cause. The investigation had as subjects 35 students of the 3rd year of high school in a state public school in the city of Porto Alegre / RS. In order to collect the data, we used researchers' Field Diary, students' written production and the audio recording of the class in which the students experienced RP. The study facilitated the development of conceptual, procedural and attitudinal contents related to scientific knowledge addressed and environmental problems related to Pesticides.
\end{abstract}

Keywords: Problem Solving. High School. Environmental Education. Pesticides. 


\section{INTRODUÇÃO}

O presente artigo faz parte de uma investigação em andamento para compor uma tese de Doutorado, cujo principal objetivo é analisar as formas de contribuição de uma sequência pedagógica implementada utilizando a metodologia da Resolução de Problemas (RP), para o desenvolvimento de conteúdos conceituais, procedimentais e atitudinais relacionados com os impactos ambientais que os Agrotóxicos podem causar, a partir de uma perspectiva interdisciplinar, com alunos de diferentes etapas e modalidades da Educação Básica (RIBEIRO et al., 2017a; RIBEIRO et al., 2017b, RIBEIRO et al., 2018a; RIBEIRO et al., 2018b). Para tanto, fundamentamos o estudo nas contribuições teóricas sobre os processos de aprendizagem propostas por Zabala (1998), nas concepções de interdisciplinaridade de Pombo (1994), assim como na perspectiva crítica de educação ambiental em Paulo Freire. Esses trabalhos científicos aplicados possuem os mesmos objetivos, entretanto, com discussões e enfoques teóricos diferentes, de acordo com cada etapa de desenvolvimento dos sujeitos da pesquisa. Neste estudo, apresentaremos a análise de uma experiência de utilização da metodologia de RP no Ensino Médio, contextualizando o tema Agrotóxicos. Nosso principal tópico de discussão neste trabalho será a concepção sobre os processos de aprendizagem (ZABALA, 1998).

Antoni Zabala, autor de referência internacional na educação, examina a correlação existente entre a proposta metodológica e as concepções de ensino que os docentes trazem consigo e expõe acerca dos processos de aprendizagem dos educandos (ZABALA, 1998). Para o autor, aprender não é apenas copiar ou reproduzir a realidade. Significa integrar conhecimentos já existentes aos novos, modificando-os e estabelecendo relação entre tais.

Sobre o ensino de Química, sabemos que os conteúdos desenvolvidos nas escolas são, em grande parte, abstratos e de complexa compreensão. O professor tem o conhecimento químico, mas em geral não consegue desenvolver os conceitos de maneira que os educandos consigam entendê-los. A forma como os conteúdos são passados aos alunos influencia de maneira direta no processo de falta de motivação do educando, uma vez que a quantidade excessiva de conteúdos, na maioria das vezes ensinados de forma confusa e superficial, contribui com os fatores que desmotivam o estudo de Química (CARDOSO; COLINVAUX, 2000).

De acordo com os Parâmetros Curriculares Nacionais (PCN) e as Orientações Curriculares Nacionais (OCN), um dos objetivos do ensino de Química é desenvolver estratégias centradas na RP, visando à aprendizagem de conceitos químicos articulados com a 
realidade natural, social e cultural e como forma de aproximar os alunos de atividades de investigação científica no contexto escolar (BRASIL, 2002, 2006).

Segundo Echeverría e Pozo (1998), uma situação somente pode ser concebida como um problema na medida em que exista um reconhecimento dela como tal, e na medida em que não disponhamos de procedimentos automáticos que nos permitam solucioná-la de forma mais ou menos imediata sem exigir, de alguma forma, um processo de reflexão ou uma tomada de decisões sobre a sequência de passos a serem seguidos, diferenciando assim um problema de um exercício. "Um problema é, de certa forma, uma situação nova ou diferente do que já foi aprendido, que requer a utilização estratégica de técnicas já conhecidas. " (ECHEVERRÍA; POZO, 1998, p. 16). Para esses autores, o principal objetivo da aprendizagem da solução de problemas é fazer com que o educando adquira o hábito de propor-se problemas e de resolvêlos como forma de aprender.

Nesse contexto, o método de RP leva os educandos a serem capazes de encarar situações do dia a dia, avaliando-as por intermédio dos modelos conceituais e também dos próprios procedimentos da Ciência. Trabalhos no campo da Química têm aventado situações de ensino por meio da metodologia de RP como procedimento para instigar o aprendizado nessa disciplina (GÓI; SANTOS, 2005; NERY, LIEGEL; FERNANDEZ, 2006).

Em estudos sobre o comprometimento que deve ter a educação escolar com a formação dos estudantes, Lipman (1995) destaca a impossibilidade de se acreditar que os estudantes poderão aprender a pensar melhor por meio de um processo educacional que pouco os estimula a pensar. $\mathrm{O}$ autor ressalta, ainda, que muitos docentes se negam a reformular seus planos de aula, pois segundo tais professores seria esse um esforço em vão quando se visa aprimorar as habilidades que os educandos já deveriam ter trazido para a sala de aula (LIPMAN, 1995).

Sabemos que a interdisciplinaridade é uma orientação que ganhou força com a Lei de Diretrizes e Bases (LDB) No 9.394/96. Desde então, muito se tem discutido sobre essa prática nas orientações curriculares e nas ações de docentes. Segundo os PCNEM, a interdisciplinaridade é, assim, entendida como abordagem teórico-metodológica com ênfase no trabalho de integração das diferentes áreas do conhecimento (BRASIL, 1999).

De forma convergente, Pombo (1994) aponta que a interdisciplinaridade pode ser compreendida como uma proposição de convergência entre duas ou mais disciplinas com o objetivo de estudo de determinado conhecimento, a partir da combinação de pontos de vista diferentes, mas com o foco na elaboração de uma síntese do referido objeto de estudo. Assim, "a interdisciplinaridade implica, então, alguma reorganização do processo de 
ensino/aprendizagem e supõe um trabalho continuado de cooperação dos professores envolvidos" (POMBO, 1994, p.13).

Nessa linha de pensamento, realizamos uma atividade entre Língua Portuguesa e Química com uma perspectiva interdisciplinar (POMBO, 1994), com o objetivo de aplicar a metodologia de RP e de contextualizar nosso trabalho com o tema ambiental Agrotóxicos. Nesse contexto, o objetivo deste estudo é avaliar as formas de contribuição da sequência pedagógica aplicada para o desenvolvimento das principais concepções sobre os processos de aprendizagem (ZABALA, 1998) relacionados com os riscos que os Agrotóxicos podem causar.

\section{REFERENCIAL TEÓRICO}

Relacionado com o principal objetivo do nosso estudo, Zabala (1998), inspirado na tipologia de César Coll Salvador, descreve tipos de conteúdo de aprendizagens: conceituais, procedimentais e atitudinais.

\subsection{A APRENDIZAGEM DOS CONTEÚDOS CONCEITUAIS}

Zabala (1998) assevera que os conceitos são termos abstratos. Para o estudioso, os conceitos dizem respeito ao conjunto de fatos, objetos ou símbolos que possuem características comuns, e os princípios estão relacionados às alterações que se produzem num fato, objeto ou situação em referência a outros fatos, objetos ou situações e que comumente especificam relações de causa-efeito ou de correlação. São exemplos de conceitos, conforme o estudioso: mamífero, densidade, impressionismo, nepotismo, etc.

Zabala (1998) assegura que não se pode afirmar que se aprendeu um conceito se não se compreendeu o significado. Para ele, saberemos que faz parte do conhecimento do aluno não apenas quando este é capaz de reproduzir sua definição, mas quando sabe usá-lo para a interpretação, compreensão ou apresentação de um fenômeno ou situação; quando é capaz de situar os fatos, objetos ou situações concretas naquele conceito que os contêm. O escritor revela que a aprendizagem de conceitos deve ser a mais significativa possível, promovendo um verdadeiro processo de elaboração e construção pessoal do conceito.

\subsection{A APRENDIZAGEM DOS CONTEÚDOS PROCEDIMENTAIS}

No que tange à aprendizagem dos conteúdos procedimentais, Zabala (1998) garante que "um conteúdo procedimental - que inclui entre outras coisas as regras, as técnicas, os métodos, as destrezas ou habilidades, as estratégias, os procedimentos - é um conjunto de ações ordenadas e com um fim", ou seja, "dirigidas para a realização de um objetivo. São conteúdos 
procedimentais: ler, desenhar, observar, calcular, classificar, traduzir, recortar, saltar, inferir, espetar, etc." (1998, p. 43)

De modo geral, segundo o estudioso, os conteúdos procedimentais são aprendidos por intermédio de modelos especializados. Para ele, a concretização de atividades que constituem o procedimento ou a estratégia é o ponto de partida. Tendo em vista essa compreensão, Zabala (1998) afirma que se aprende a realizar uma ação realizando-a, e que é necessário executá-la tantas vezes quantas forem precisas até ser capaz se de refletir acerca do modo de realizá-la e sobre quais as condições ideais de sua utilização em contextos diferenciados.

\subsection{A APRENDIZAGEM DOS CONTEÚDOS ATITUDINAIS}

No que diz respeito à aprendizagem dos conteúdos atitudinais, Zabala (1998) declara que o termo conteúdos atitudinais compreende uma variedade de conteúdos que, por seu turno, podem-se agrupar em valores, atitudes e normas.

Assim sendo, valores são os princípios ou as ideias éticas que possibilitam as pessoas enunciar um juízo acerca das condutas e seu sentido, dando como exemplos: a solidariedade, o respeito aos outros, a responsabilidade etc. $\mathrm{O}$ autor considera que se adquiriu um valor quando este foi interiorizado e foram concebidos critérios para posicionar-se em relação ao que se deve julgar positivo ou negativo, preceitos morais que conduzem o desempenho e a avaliação de si mesmo e dos outros. Esse valor que terá um maior ou menor suporte reflexivo, mas cuja peçachave é o elemento cognitivo. Atitudes são tendências ou predisposições parcialmente estáveis dos indivíduos com o intuito de atuar de certo modo. São a maneira como cada pessoa realiza seu comportamento, consoante valores definidos. Dessa maneira, o escritor dá exemplos como: cooperar com o grupo, auxiliar os colegas, respeitar o meio ambiente, envolver-se com as tarefas escolares etc. Para Zabala (1998), “Aprendeu-se uma atitude quando a pessoa pensa, sente e opera de uma forma mais ou menos constante frente ao objeto concreto a quem dirige essa atitude" (p. 47). Normas são modelos ou regras de comportamento que precisamos seguir em certas situações que obrigam a todos os componentes de um grupo social. Alguns exemplos citados pelo autor: normas de trânsito, padrões sociais de comportamento etc.

De uma maneira geral, em consonância com o que declara o autor, a aprendizagem dos conteúdos atitudinais pressupõe um conhecimento e uma reflexão acerca dos possíveis padrões, uma apreciação e uma avaliação das regras, uma apropriação e criação do conteúdo, que visa à apreciação dos elementos positivos e negativos, um posicionamento, um envolvimento afetivo e uma revisão e avaliação da própria atuação. 


\section{METODOLOGIA DE PESQUISA}

O presente artigo caracteriza-se por ter um caráter qualitativo (LÜDKE; ANDRÉ, 1986), já que este tipo de pesquisa costuma ser direcionada, ao longo de seu desenvolvimento. Além disso, não procura enumerar ou mensurar eventos e, geralmente, não se utiliza de instrumental estatístico para análise dos dados. O foco de interesse deste tipo de pesquisa é amplo e parte de uma perspectiva diferenciada da adotada pelos métodos quantitativos. Dela faz parte a obtenção de dados descritivos mediante contato direto e interativo do pesquisador com a situação objeto de estudo. Nas pesquisas qualitativas, é frequente que o pesquisador procure entender os fenômenos, segundo a perspectiva dos participantes da situação estudada e, a partir de então, estabeleça sua interpretação dos fenômenos estudados. Apesar de termos dados numéricos, a análise está centrada nos significados dos resultados e não nos valores numéricos em si.

Dentre as modalidades que a pesquisa qualitativa nos oferece, utilizamos o Estudo de Caso (YIN, 2001). O Estudo de Caso contribui para compreendermos melhor os fenômenos individuais, os processos organizacionais e políticos da sociedade. É uma ferramenta utilizada para entendermos a forma e os motivos que levaram a determinada decisão. Conforme Yin (2001), o estudo de caso é uma estratégia de pesquisa que compreende um método que abrange tudo em abordagens específicas de coletas e análise de dados.

O Estudo de Caso descrito neste trabalho foi desenvolvido com 35 alunos do $3^{\circ}$ ano do Ensino Médio, turno diurno, de uma escola pública estadual da cidade de Porto Alegre/RS, sendo os pesquisadores professores dos sujeitos deste trabalho. Todos os participantes ou responsáveis assinaram Termo de Consentimento Livre e Esclarecido.

Os dados foram coletados por meio de registros no Diário de Campo (PORLÁN; MARTÍN, 1998) dos pesquisadores, das produções escritas produzidas pelos educandos, da aplicação de questionário e da gravação do áudio da aula, para posterior análise de conteúdos. Essa metodologia se caracteriza como um dos procedimentos clássicos para interpretar materiais textuais. Segundo Bardin (2010), a Análise de Conteúdo é "um conjunto de técnicas de análise das comunicações que utiliza procedimentos sistemáticos e objetivos de descrição do conteúdo das mensagens", além de possibilitar "a interferência de conhecimentos relativos às condições de produção (ou, eventualmente, de recepção), interferência esta que recorre a indicadores (quantitativos ou não) $"$ (p. 40). 


\subsection{Metodologia Pedagógica}

Nesta pesquisa, tendo alunos do Ensino Médio regular como sujeitos do trabalho aplicado, realizamos a análise de um experimento da utilização da metodologia de RP. Para isso, contextualizamos o tema Agrotóxicos, sua descrição, uso e diversas possibilidades para essas substâncias químicas. Os educandos experienciaram a metodologia da RP na sala de vídeo de seu estabelecimento de ensino. Com o intuito de todos participarem da totalidade dos estágios do estudo, a experiência ocorreu em um único encontro de seis períodos contínuos. Para o bom andamento da investigação, empregamos uma sequência didática que abrangeu seis momentos, como demonstramos no Quadro 1.

Quadro 1. Sequência didática

\begin{tabular}{|c|l|}
\hline Momentos & \multicolumn{1}{c|}{ Atividades } \\
\hline I. & $\begin{array}{l}\text { Introdução dos alunos ao tema, por intermédio de um vídeo de motivação (“O Veneno está na } \\
\text { mesa 1” disponível em https://www.youtube.com/watch?v=fnyZwI7022I) e da explanação feita } \\
\text { pelos pesquisadores sobre os problemas ambientais que os Agrotóxicos podem causar, } \\
\text { propiciando a discussão com os estudantes sobre os conteúdos e contextos presentes nos } \\
\text { problemas a serem resolvidos; }\end{array}$ \\
\hline II & $\begin{array}{l}\text { Organização das equipes de trabalho em cinco grupos de seis pessoas e um grupo de cinco } \\
\text { pessoas, seguida da leitura e análise dos problemas, que foram apresentados no decorrer da } \\
\text { discussão do presente trabalho; }\end{array}$ \\
\hline III. & $\begin{array}{l}\text { Discussão dentro dos grupos para elaboração das hipóteses de trabalho e leitura dos materiais } \\
\text { disponíveis para consulta, que incluíram o livro didático das Ciências da Natureza e } \\
\text { Matemática da Educação de Jovens e Adultos (SCRIVANO, et al., 2013) e os três volumes do } \\
\text { livro didático de Química (SANTOS; MÓL, 2013), adotados pela escola pelo Programa } \\
\text { Nacional do Livro Didático. }\end{array}$ \\
\hline IV & Elaboração das apresentações com as resoluções; \\
\hline V. & Plenária de apresentação das resoluções; \\
\hline VI. & $\begin{array}{l}\text { Debate coletivo, no qual os professores formadores realizaram um levantamento sobre as } \\
\text { principais modelações de resolução e ressaltaram os conceitos fundamentais discutidos. }\end{array}$ \\
\hline
\end{tabular}

Em consonância com Pozo e Crespo (1998), os problemas propostos podem ser categorizados como escolares, os quais possuem como meta desenvolver conceitos, procedimentos e atitudes adequadas à ciência as quais viabilizam a compreensão dos fatos cotidianos; semiabertos, já que os enunciados exibem parcialmente os meios indispensáveis para a sua resolução; qualitativos, uma vez que os educandos podem utilizar conceitos científicos e teorias, sem precisar de cálculos ou raciocínio matemático; e teórico-práticos, pois admitem métodos experimentais e raciocínios teóricos para solucioná-los. No que diz respeito aos problemas semiabertos e qualitativos, enfatizamos que eles viabilizam que os próprios alunos agreguem ideias e estratégias com as quais a tarefa possa ser definida e solucionada.

Assim sendo, os três problemas criados pelos pesquisadores, versam acerca da temática Agrotóxicos para que pudéssemos aprofundar o estudo dos conteúdos envolvidos nessa questão. 
O Problema 1 "Combater pragas de lavouras, insetos ou animais transmissores de doenças sempre foi um grande desafio. Afinal, boa parte da produção se perde, vítima desses agentes. A Química entrou nessa batalha produzindo substâncias que amenizam esse problema, os chamados Agrotóxicos. Você é professor de Química de uma zona rural de Porto Alegre e descobriu que alguns dos seus alunos são agricultores e não utilizam roupas de proteção apropriadas na aplicação de Agrotóxicos nas lavouras. Você dará aula para esses estudantes e outros que também precisam saber sobre os cuidados que devem ter com os Agrotóxicos. Faça uma pesquisa a respeito da definição de Agrotóxicos e a finalidade para a qual são utilizados na agricultura. Dê exemplo de um defensivo agrícola, seu nome, estrutura química e os problemas de saúde e danos ao organismo humano que esse Agrotóxico e outros podem causar. O que os agricultores podem fazer para amenizar os riscos à saúde no momento da aplicação de Agrotóxicos? " parte da descrição da maneira pela qual os Agrotóxicos relacionam-se ao ensino de Química e visava, em sua elucidação, que os educandos compreendessem que essas substâncias químicas provocam sérias consequências à saúde humana. Ademais, outra finalidade era expor que a utilização de vestimentas adequadas, tais como: máscaras, botas, luvas etc., quando são empregados Agrotóxicos ainda não faz parte do hábito de grande parte dos agricultores brasileiros.

O Problema 2 "Grande parte dos municípios brasileiros tem a agricultura como principal atividade econômica. Devido a doenças e ervas daninhas, os agricultores utilizam Agrotóxicos para controlar essas pragas. Agrotóxicos são produtos utilizados na agricultura para controlar insetos, doenças, ou plantas daninhas que causam danos às plantações. Os Agrotóxicos também podem ser chamados de defensivos agrícolas ou agroquímicos, mas apesar dos diferentes nomes, todos possuem o mesmo significado. Você foi contratado para analisar e resolver o problema da pulverização de Agrotóxico em um arrozal. O Agrotóxico é pulverizado por aviões em lavouras de arroz, mas nas imediações há moradores, animais e um rio corta a plantação. Quais seriam as consequências de realizar uma aplicação aérea de Agrotóxicos sem um estudo prévio das condições meteorológicas e do entorno dessa pulverização? Pesquise sobre as alternativas para o cultivo de agriculturas sem a utilização de Agrotóxicos ou, pelo menos, para redução de seu uso. Discuta, também, quais as vantagens e desvantagens de cada uma dessas alternativas e decida quais delas você considera mais eficiente para diminuir o uso de Agrotóxicos. " associava-se aos métodos de aplicação de Agrotóxicos nas lavouras com possibilidades de substituição dessas substâncias químicas. Tendo em vista a questão proposta, era nossa esperança que os educandos tivessem a 
compreensão de que a análise das condições meteorológicas é primordial na pulverização de Agrotóxicos na lavoura. Isso se deve ao fato de a utilização de Agrotóxicos exigir voos de baixa altura, os quais possuem elevada possibilidade de queda das aeronaves em condições de chuva e fortes ventos. Outro motivo preocupante é que o Agrotóxico, além de lixiviar, tem a probabilidade de atingir áreas adjacentes, conforme a direção do vento, contagiando o meio ambiente. No que tange às opções com o intuito da substituição de Agrotóxicos, era nossa intenção que os estudantes entendessem que há diversas alternativas e que todas as escolhas apresentam vantagens e desvantagens.

O Problema 3 "O desenvolvimento tecnológico contribui de forma significativa para o aumento da produtividade agrícola, elevando a quantidade de alimentos produzida por área cultivada. Esse aumento de produtividade possibilitou uma maior disponibilidade de alimentos para a população. No entanto, a exploração agrícola tem sido a principal responsável pela destruição de áreas verdes, provocando desmatamentos, desertificação de grandes áreas, além do que o uso intensivo de produtos químicos na lavoura tem provocado sérios problemas ambientais. Diante disso, a agricultura orgânica tem aumentado muito no Brasil e tem tido um mercado promissor. $O$ alimento orgânico é originário do reino vegetal e cultivado sob circunstâncias específicas sem uso de Agrotóxicos, pesticidas, hormônios e outros. Pesquise a respeito da agricultura orgânica, seus princípios, suas práticas de cultivo, vantagens, desvantagens etc. Dê um exemplo de controle natural de pragas com aplicação de conhecimentos químicos e como alternativa para os Agrotóxicos. " aborda questões ambientais que a exploração agrícola pode acarretar. Assim sendo, nesse ambiente a nossa solicitação foi que os educandos pesquisassem acerca da agricultura orgânica com o intuito de que os mesmos compreendessem que a produção com a utilização de Agrotóxicos pode levar ao comprometimento da saúde e do ambiente, mesmo que haja elevação da produtividade agrícola. Todavia, a agricultura orgânica objetiva aprimorar a qualidade dos alimentos sem a contaminação dos produtores e consumidores, considerando e conservando o ambiente. Ademais, a questão proposta propunha-se a expor aos estudantes que existem diferentes alternativas para o controle de insetos sendo desenvolvidas, tais como: utilização de predadores naturais, método intitulado controle biológico, esterilização por radiação nuclear, rodízio de culturas, desenvolvimento de novas espécies por engenharia genética e controle químico com o uso de feromônios.

Após o término da sequência didática, para o fechamento das atividades, aplicamos um questionário, com o objetivo de avaliarmos a contribuição da metodologia de RP no 
entendimento e compreensão dos conteúdos pelos alunos, bem como o desenvolvimento de habilidades de análise, de raciocínio, de organizações e informação, de classificação, de investigação, de tomada de decisão, como apontamos no referencial teórico. Como o desenvolvimento da atividade aconteceu em um encontro contínuo, os trinta e cinco alunos responderam ao questionário.

\section{RESULTADOS E DISCUSSÃO}

\subsection{DA MOTIVAÇÃO ÀS HIPÓTESES}

Com o intuito de introduzir a atividade proposta e motivar os educandos para a temática Agrotóxicos relacionada à metodologia de RP, o pesquisador $\mathrm{Q}$ (professor de Química) questionou os educandos sobre o que são Agrotóxicos. Consoante às anotações do Diário de Campo, percebemos que a participação do grupo discente foi bastante expressiva. Um aluno respondeu que Agrotóxicos são venenos. Dessa forma, o pesquisador Q questionou para quem os Agrotóxicos são um veneno. O mesmo aluno disse que os Agrotóxicos são venenos para as pessoas. Outra aluna afirmou que são venenos também para as plantas. Um terceiro aluno assegurou que os Agrotóxicos são uma espécie de inseticida usados na agricultura para livrar as plantações de pragas que possam vir a prejudicar essas plantações. Outra estudante asseverou que Agrotóxicos são produtos que usamos para combater insetos, doenças ou plantas daninhas que causam danos às plantações. Dando continuidade às perguntas, o docente interrogou a turma sobre se os Agrotóxicos são bons para os seres humanos e para o meio ambiente. Uma educanda declarou que os Agrotóxicos não são bons para os seres humanos, pois podem causar danos à saúde e nem para o meio ambiente, uma vez que podem causar a poluição do solo e das águas. Seguindo as arguições, um aluno expôs que os Agrotóxicos podem causar tumores e, consequentemente, o surgimento de câncer quando utilizados acima dos limites permitidos ou quando se empregam Agrotóxicos proibidos, causando má-formação de bebês e alterações hormonais. Também não são bons para o meio ambiente, já que poluem o solo e as nascentes de rios. Devido ao interesse da turma, o pesquisador Q lançou um outro questionamento, indagando-os sobre se as plantas são mais saudáveis com ou sem Agrotóxicos e por quê. Uma aluna afirmou que com Agrotóxicos as plantas não seriam atacadas por pragas, mas seriam mais saudáveis sem essas substâncias, porque não teriam nenhuma interferência de produtos químicos. Um outro estudante asseverou que as plantas seriam mais saudáveis sem Agrotóxicos, mas se houvesse um tipo de produto que não fizesse mal aos seres humanos, ao meio ambiente $\mathrm{e}$ às plantas esse produto seria bem-vindo. Aproveitando a afirmação desse 
último aluno, o pesquisador Q, por intermédio de perguntas condutoras, fez com que os alunos chegassem à conclusão de que os Agrotóxicos são prejudiciais à saúde humana, danosos ao meio ambiente: ao solo, aos rios e aos animais e explicou-lhes a respeito da agricultura orgânica e seus benefícios. Uma aluna chegou à conclusão, por intermédio das explanações do pesquisador $\mathrm{Q}$, de que a agricultura orgânica é mais cara. O docente esclareceu que ela pode ser mais barata se houver incentivo do governo. Outra aluna deu sua contribuição à discussão, afirmando que sua sogra possui uma horta em seu quintal e não utiliza nenhum tipo de Agrotóxico, o máximo que ela usa é sal para afugentar algumas pragas. Um aluno garantiu que é mais fácil e barato largar Agrotóxicos sobre as plantas. Uma vez mais, o pesquisador Q ressaltou que o governo incentiva a agricultura com Agrotóxicos e que a agricultura orgânica não possui incentivo do governo, por isso é mais cara.

Vale destacar que os Agrotóxicos podem ser definidos como produtos designados ao uso nos setores de produção, armazenamento e beneficiamento de produtos agrícolas nas pastagens, na proteção de florestas, em ambientes urbanos, hídricos e industriais, com a finalidade de alterar a composição da fauna e da flora, a fim de conservá-las da ação danosa de seres vivos ponderados nocivos (SANTOS; MÓL, 2013).

Os ingredientes ativos presentes nos Agrotóxicos possuem elevado grau de toxidade aguda comprovada e causam problemas neurológicos, reprodutivos, de desequilíbrios hormonais e até câncer. Contudo, esses Agrotóxicos são vendidos normalmente no Brasil. Apesar de serem proibidos em vários locais do mundo, como União Europeia e Estados Unidos, há pressões do setor agrícola para manter esses produtos (endosulfan, metamidofós e acefato) no Brasil, mesmo após serem retirados de forma voluntária em outros países. (ANVISA, 2009 apud RIBEIRO, 2016).

Acreditamos que a finalidade precípua da escola é desenvolver a formação integral do aluno, por intermédio de uma aprendizagem que privilegie experiências vividas pelos estudantes e os faça refletir profundamente sobre a realidade que os cerca e possam tornar-se cidadãos críticos e reflexivos, tendo em vista o contexto social em que vivem. Já discutimos, neste trabalho, que a metodologia de RP converge para isso, pois nesse tipo de método o professor não é o centro da aprendizagem, mas o orientador do processo de aprendizagem dos educandos, deixando de ser "o mestre conteudista" e dando aos estudantes a oportunidade se desenvolverem em seus aspectos cognitivo, motor, afetivo e atitudinal, como os necessários para a conscientização sobre os riscos causados pelos Agrotóxicos. 
Dessa maneira, tendo em vista um diálogo constante com o grupo discente, o pesquisador Q, sendo um mediador da aprendizagem, trouxe à tona opiniões e conhecimentos prévios dos educandos, estimulando-os à participação, à reflexão e à busca de respostas. Essa afirmação é corroborada por Cury (2003) quando assegura que "a exposição interrogada gera a dúvida, a dúvida gera o estresse positivo, e este estresse abre as janelas da inteligência. Assim formamos pensadores, e não repetidores de informações" (p. 127).

Na mesma linha de pensamento, Soares e Pinto (2001) afirmam que há uma necessidade de os docentes perceberem seu papel orientador, "mediador das ideias apresentadas pelos alunos, de modo que estas sejam produtivas, levando os estudantes a pensarem e a gerarem seus próprios conhecimentos". (p.7)

Terminada essa discussão, que mostrou um interesse bastante grande por parte dos educandos, os quais participaram ativamente, o pesquisador Q, por intermédio de PowerPoint, começou a explicar o assunto a ser tratado, qual seja: “Agrotóxicos e Resolução de Problemas”.

Realizada a apresentação dos princípios da proposta pedagógica e do contexto na qual a mesma se insere, organizamos a sequência didática apresentada na metodologia, com o objetivo de efetivar o exercício de RP com os educandos.

No decorrer da apresentação do vídeo, (Momento I) a turma revelou-se muito concentrada, solicitando aos pesquisadores, inclusive, onde poderiam encontrar o vídeo para assistirem fora da escola. O pesquisador $\mathrm{Q}$, em diversos momentos, parou o filme para dar maiores explicações aos fatos narrados. Após a organização da turma em seis grupos (Momento II), o pesquisador $\mathrm{P}$ passou às mãos dos educandos os problemas a serem solucionados e requereu que lessem atenciosamente a folha recebida, esclarecendo-a. Foram entregues aos grupos três problemas, isso significa, então, que houve sempre dois grupos com as mesmas questões. Nessa etapa, os educandos foram alertados de que precisariam formular hipóteses de resolução para os problemas apresentados. Pelo que pudemos observar, os grupos não tiveram dificuldades relacionadas ao entendimento das proposições dos problemas e pesquisaram as informações necessárias às atividades propostas nos subsídios recomendados pelos pesquisadores. Para a elaboração das hipóteses de trabalho (Momento III), os grupos realizaram a leitura dos materiais disponíveis para consulta. À proporção que os alunos trabalhavam, os pesquisadores circulavam entre os grupos para auxiliá-los em possíveis dúvidas, indagando os estudantes a respeito de suas hipóteses, tentando, por intermédio de perguntas condutoras, leválos à reflexão e à crítica a respeito do que estavam realizando. 
De acordo com Carvalho e Gil-Pérez (2006), os docentes adotam o papel de orientadores e mediadores nas atividades de investigação dirigida. Assim sendo, podem debater acerca do problema em questão, criando relações para que os educandos possam entendê-lo, auxiliar no acesso a outras fontes de conhecimento e discutir os dados obtidos interligando-os com as hipóteses apuradas, para averiguar se a tarefa está efetivamente sendo realizada pelos caminhos utilizados. As obras didáticas que fizeram parte da busca de informações por parte dos educandos para a resolução dos problemas apresentados possuem esclarecimentos pontuais sobre o uso dos Agrotóxicos: definição, finalidade, consequências, características químicas e alternativas de substituição. Por esse motivo, percebemos que, para essa proposta pedagógica, os materiais utilizados foram suficientes para tratar a temática Agrotóxicos convergindo com as orientações propostas para o Ensino Médio (BRASIL, 1999, 2002, 2006).

Para a apresentação das resoluções dos problemas, os alunos realizaram um relatório e confeccionaram cartazes relacionados aos problemas (Momento IV). Isso os ajudou na explanação das hipóteses levantadas, bem como a explicitar como haviam solucionado os problemas a eles destinados. $\mathrm{O}$ que observamos foi uma desenvoltura nas apresentações por parte dos estudantes que mostraram, durante todo o processo da resolução das questões propostas, muito interesse e dedicação, discutindo entre si possíveis soluções e questionando, sempre que necessário, os pesquisadores.

\subsection{AS RESOLUÇÕES E APRESENTAÇÕES}

A análise a seguir foi feita a partir do áudio das apresentações dos grupos (Momento V), apontamentos no diário de campo, análise dos relatórios escritos e cartazes confeccionados pelos grupos. O problema 1 foi solucionado pelos grupos 1 e 2 . O grupo 1 explicou adequadamente a resolução do problema, apresentando para o mesmo sugestões plausíveis. Além disso, para esse grupo, a diminuição do uso de Agrotóxicos poderia ser feita por intermédio de palestras que ensinassem o uso correto desses produtos químicos e a divulgação da agricultura orgânica. Já o grupo 2, teve dificuldade em falar sobre os problemas de saúde que os Agrotóxicos podem causar. Coube aos grupos 3 e 4 solucionar o problema 2. Ambos os grupos conseguiram perceber que há possibilidades para se substituírem os Agrotóxicos, entretanto tiveram dificuldade em perceber que cada uma das alternativas possui vantagens e desvantagens. Entenderam os cuidados que seriam necessários para uma aplicação aérea de Agrotóxicos nas lavouras. Os grupos 5 e 6 trabalharam com o problema 3. O grupo 5 não teve grandes dificuldades em resolvê-lo e propôs uma resolução próxima da esperada. O grupo 6 
não falou sobre as vantagens e desvantagens da agricultura orgânica, entretanto articulou informações sobre adubos orgânicos e utilização racional de recursos hídricos sem contaminálos.

Achamos pertinente destacar, nesse momento, a produção dos cartazes feitos por todos os grupos. No geral, identificamos uma boa organização das informações relacionadas à temática ambiental Agrotóxicos, sendo que, em alguns casos, percebemos como nossos estudantes podem ter a criatividade estimulada a partir de um tema (Figura 1) e conseguirem, a partir disso, expor suas ideias de maneira a ajudá-los a construírem seus próprios conhecimentos.

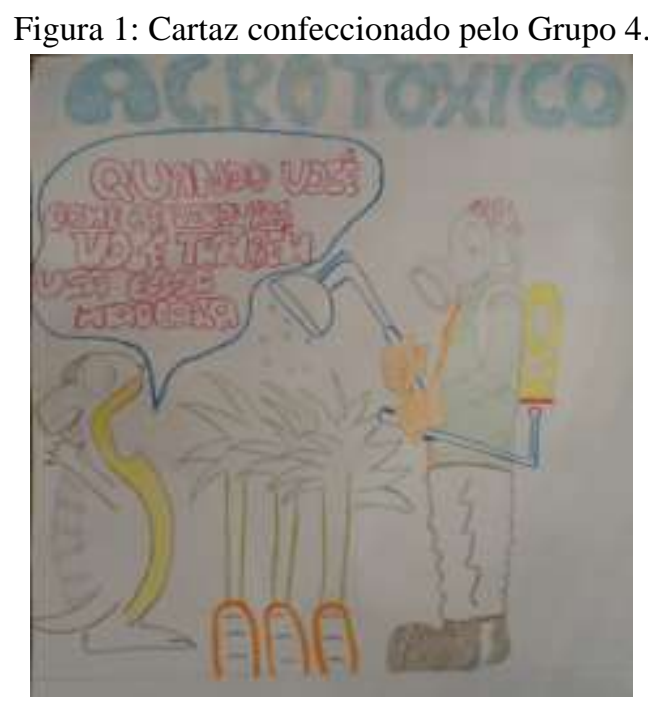

Fonte: Apresentação Grupo 4.

No Momento VI, os professores administraram a discussão sobre as resoluções apresentadas, as dificuldades enfrentadas e os conceitos fundamentais abordados. Explicaram as consequências da utilização de Agrotóxicos, fazendo um apanhado das apresentações feitas pelos educandos, identificando as dificuldades e o que os alunos não conseguiram resolver nos problemas. De acordo com os apontamentos do Diário de Campo, os pesquisadores, por intermédio de perguntas condutoras, e a partir das afirmações dos alunos e das resoluções dos problemas propostas por eles, fizeram com que os estudantes chegassem à conclusão de que os Agrotóxicos são prejudiciais ao meio ambiente: seres vivos, solo, rios, ar, plantas etc. Percebemos também um grande interesse dos educandos a respeito de como fazer para tirar ou diminuir o Agrotóxico dos alimentos comprados. No momento dos questionamentos, os docentes explicaram, fornecendo algumas dicas como: Comprar preferencialmente frutas e verduras da época, já que para serem produzidas fora de tempo recebem elevada carga de Agrotóxicos; retirar a gordura de todas as carnes e também a pele de aves, porque os resíduos 
de produtos químicos, como os Agrotóxicos, hormônios e antibióticos, tendem a se concentrar na gordura; procurar reduzir o consumo dos produtos convencionais que mais recebem dosagens de Agrotóxicos (pêssego, maçãs, uvas, figos, goiabadas, morangos, peras, papaias, melões, nectarinas e tomates), tentando substituí-los por produtos orgânicos.

Durante as atividades realizadas com os educandos, pudemos perceber os tipos de aprendizagens descritas por Zabala (1998), ou seja, aprendizagens de conteúdos conceituais, procedimentais e atitudinais. Dessa maneira, quando os pesquisadores iniciaram o trabalho e, por intermédio de perguntas condutoras, ativaram os conhecimentos prévios dos alunos acerca de Agrotóxicos estavam buscando conceitos já socialmente produzidos sobre o tema tratado, informações que os educandos conheciam em menor ou maior grau, demonstrando uma aprendizagem de conteúdos conceituais. O entendimento dos vídeos apresentados, as discussões realizadas sobre a temática ambiental abordada, as resoluções dos problemas só foram possíveis tendo em vista os conteúdos conceituais por parte dos aprendizes aliados às novas informações recebidas, tornando esses conteúdos mais sólidos. Os conteúdos conceituais exigem compreensão e dependem de atividades que suscitem um processo de construção pessoal, que favoreça atividades em que os alunos vivenciem o conteúdo, ativando os conhecimentos prévios dos estudantes. Como se pôde observar, nossas ações convergiram para a aprendizagem de conteúdos conceituais. Da mesma forma, notamos, ao final do trabalho, que o conceito de Agrotóxicos para a maioria dos alunos ficou mais consolidado por intermédio dos debates e pesquisas realizados, assim como as consequências danosas desses produtos químicos. Segundo Zabala (1998), "Uma das características dos conteúdos conceituais é que a aprendizagem quase nunca pode ser considerada acabada, já que sempre existe a possibilidade de ampliar ou aprofundar seu conhecimento, de fazê-la mais significativa. ” (p. 43)

No que diz respeito aos conteúdos procedimentais, que englobam objetivos, resultados e meios para atingi-los, articulados por ações, passos ou procedimentos a serem implementados e aprendidos Zabala (1998) nos afirma que são conteúdos procedimentais: ler, desenhar, observar, calcular, classificar, traduzir, recortar, inferir etc. Dessa maneira, quando os problemas foram entregues aos grupos para serem resolvidos os alunos tiveram de lê-los com o intuito de compreendê-los e, até mesmo, inferir algumas informações neles contidas. As situações apresentadas nos problemas valorizavam o senso-comum, relacionando-o com o cotidiano do aluno. Além disso, para chegarem a um resultado para as questões propostas houve, por parte dos aprendizes, formulação de hipóteses e suposições. Ao lerem os materiais disponíveis para a solução dos problemas, os alunos organizaram informações para o relatório 
escrito, inclusive por meio de desenhos, uma vez que para a apresentação oral das resoluções tiveram de criar cartazes e os desenhos os auxiliaram grandemente na organização mental para expressarem oralmente os resultados obtidos. Outrossim, as atividades propostas incentivaram a escrita, a leitura e a interpretação de textos informativos, além do vídeo (O Veneno Está na Mesa I) fontes consideradas pelos pesquisadores confiáveis para reforçarem a aprendizagem dos conteúdos procedimentais.

Tendo em vista a aprendizagem dos conteúdos atitudinais, que se referem à formação de atitudes, valores em relação à informação recebida, visando à intervenção do educando em sua realidade, por intermédio da vivência do ser com o mundo que o rodeia a metodologia apresentada propiciou esse tipo de aprendizagem. A composição da turma em grupos, por exemplo, beneficiou o trabalho para a aprendizagem de conteúdos atitudinais que, segundo Zabala (1998), engloba conteúdos os quais podem se agrupar em valores, atitudes e normas. Dessa maneira, para o autor os valores são a solidariedade, o respeito aos outros, a responsabilidade, a liberdade etc. Esses valores foram observados pelos pesquisadores no decorrer do trabalho em grupo, já que os componentes do grupo auxiliaram-se em relação a dúvidas, empréstimo de material, respeitaram opiniões divergentes sobre os Agrotóxicos e as maneiras de solucionar ou diminuir os danos causados por eles com o objetivo de chegarem a um senso comum no momento de apresentarem suas resoluções. Pelas observações realizadas, os elementos do grupo agiram com responsabilidade, pois cada um teve uma tarefa e a cumpriu a contento, assim como tiveram a liberdade para trabalharem da maneira que os aprouvesse, a fim de chegarem aos seus objetivos. Além do mais, diagnosticaram e propuseram soluções para o problema ambiental a eles destinados, verificaram relações sustentáveis entre a espécie humana e o meio ambiente. Da mesma forma, a metodologia apresentada estimulou a diversidade de opiniões, levando os educandos a posicionarem-se crítica e construtivamente, respeitando as opiniões dos demais grupos.

As avaliações dos estudantes a respeito da proposta que foi apresentada foram colhidas por meio das perguntas um, dois e três do questionário aplicado após o término da sequência didática. Na questão um, foram apresentadas aos alunos algumas afirmativas que dizem respeito a habilidades, conceitos e capacidades que pretendíamos aprimorar com a metodologia de RP. Na Figura 2, mostramos o grau de concordância dos alunos com as afirmações apresentadas. 
Figura 2: Grau de concordância dos alunos

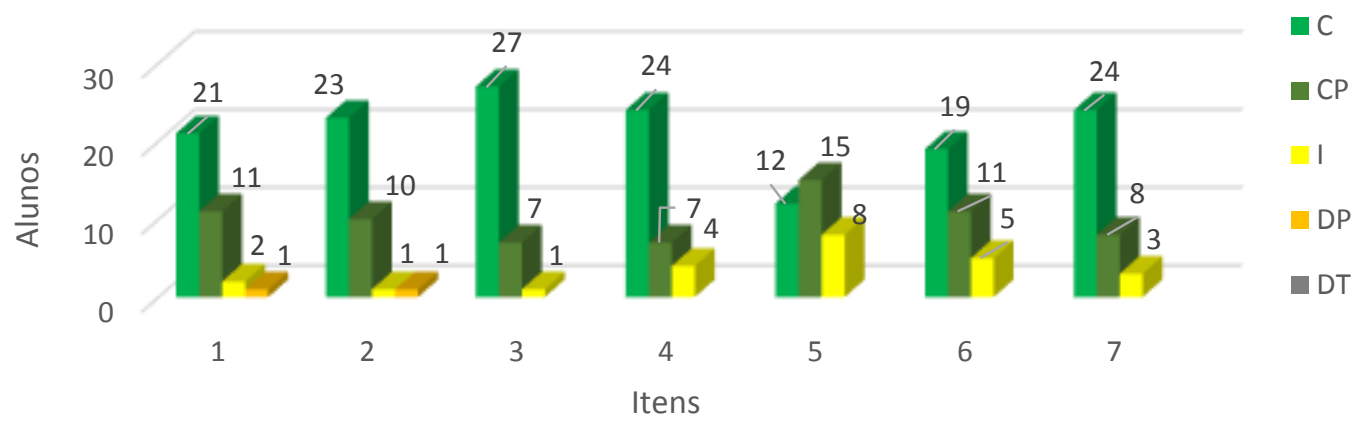

Grau de concordância dos alunos em relação às afirmações apresentadas nos itens que vão de 1 a 7 (1Desenvolvi minha habilidade de investigação na busca de soluções para resolver o caso; 2 - Desenvolvi minha habilidade de organizar informações; 3- Desenvolvi minha habilidade de raciocínio; 4- Desenvolvi minha habilidade de análise; 5- Desenvolvi minha habilidade de classificação; 6- Desenvolvi minha capacidade de solucionar problemas e tomar decisões diante de problemas da vida real 7- A metodologia de Resolução de Problemas contribuiu para a aprendizagem de conhecimentos de Ciências da Natureza e utilização da Língua Portuguesa) sobre a RP. Onde $\mathrm{C}=$ concordo; $\mathrm{CP}=$ concordo parcialmente; $\mathrm{I}=$ indeciso; $\mathrm{DP}=$ discordo parcialmente; DT = discordo totalmente.

Fonte: Elaborado pelos autores com base nos dados coletados no questionário final.

A análise da Figura 2 permite afirmar que nos itens 1, 2, 3, 4 e 5, que dizem respeito ao desenvolvimento das habilidades de investigação, raciocínio, análise e classificação, respectivamente, a maioria dos alunos registrou respostas favoráveis à contribuição da metodologia de RP para o seu aprimoramento. Lipman (1995) acredita que tais habilidades são relevantes para se alcançar objetivos educacionais, como a educação científica para o exercício da cidadania. Apesar de alguns itens apresentarem algumas respostas desfavoráveis à contribuição da metodologia, o resultado geral aponta para a efetividade da proposta de ensino no desenvolvimento das referidas habilidades, na opinião dos estudantes. No item 6 , trinta estudantes concordaram com a contribuição da metodologia para o desenvolvimento da capacidade de solucionar problemas e tomar decisões diante de problemas da vida real; apenas cinco alunos ficaram indecisos nesse item. E no item sete, que diz respeito às impressões dos estudantes sobre a contribuição da metodologia para a aprendizagem de conhecimentos de Ciências da Natureza e a utilização da disciplina de Língua Portuguesa, trinta e dois alunos foram favoráveis à sua aplicação, e uma pequena minoria (três alunos), novamente, ficaram indecisos nesse item. Entendemos que os resultados refletem a participação e o envolvimento dos estudantes durante o trabalho que foi proposto, e a atividade que foi realizada em grupo contribuiu para a formação dos educandos.

$\mathrm{Na}$ questão de número dois, solicitamos que os educandos comentassem a respeito do trabalho interdisciplinar realizado com professores de Química e Língua Portuguesa, aplicando a metodologia de RP. Três alunos usaram termos como "diferente" e "novidade", mas não 
aprofundaram suas repostas. Entendemos que quando utilizaram esses termos em suas argumentações, os alunos estavam comparando com o método tradicional de ensino ${ }^{1}$. Já a grande maioria dos estudantes, vinte educandos, afirmaram que gostaram de trabalhar com uma aula interdisciplinar, dizendo que foi uma aula interessante, legal e/ou boa: "Achei bem legal, um modo melhor de aprender, as matérias interagindo", "O trabalho interdisciplinar foi um tanto curioso para mim. Foi bom, incluindo mais de uma matéria em uma aula", "Foi algo muito interessante a ideia de trabalhar duas matérias como uma mesma disciplina relacionada para um mesmo propósito: A aprendizagem”.

Notamos que a compreensão dos alunos sobre interdisciplinaridade é convergente àquela apresentada por Pombo (1994), evidenciando que deve existir um trabalho em conjunto entre os professores das diferentes disciplinas, com objetivos convergentes, visando trabalhar assuntos a partir de pontos de vista diferentes.

Ainda analisando as respostas dos alunos na pergunta dois, verificamos que sete alunos além de acharem uma metodologia diferente e inovadora aprofundaram suas argumentações favoravelmente a esse método de ensino: "Gostei bastante, porque foi uma aula diferente $e$ mais compreendida”, “...foi uma maneira diferente de aprender, acredito que bem mais fácil de entender e guardar o que aprendeu", "Foi uma experiência diferente, mas muito produtiva", "É uma experiência diferente das que possuímos no dia a dia, escolar, mas foi muito bom. Deveria ser aplicada mais vezes".

Outros cinco educandos expuseram suas ideias sobre a aula interdisciplinar aplicada pelos professores de Química e Língua Portuguesa, falando sobre a aprendizagem e conhecimentos que adquiriram: "É melhor assim, os alunos aprendem mais e interagem mais com a aula", "Foi uma maneira de juntar diferentes tipos de conhecimentos para resolver um problema".

A pergunta três do questionário aplicado no final da pesquisa indagava os alunos se os mesmos gostaram de trabalhar com a metodologia de RP. Todos os trinta e cinco estudantes afirmaram que gostaram da atividade escolar utilizando essa metodologia: "Sim, porque acabamos entendendo mais sobre os assuntos propostos", "Sim, instiga a atenção, faz com que

\footnotetext{
${ }^{1}$ Os métodos tradicionais de ensino podem originar vários problemas. A insistência na imitação, obediência e repetição, muito frequente nestes métodos, conduzem a uma negligência das capacidades criativas individuais em detrimento de competências que são puramente mecânicas e repetitivas. Abandonar esta concentração rígida no intelecto humano a favor de uma pessoa holística que deve ser encorajada, fortalecida e motivada aumentaria imensamente as capacidades dessa pessoa.
} 
se interessa mais e entenda melhor o problema", "Sim, porque aprendi melhor sobre como solucionar problemas, apresentando as estratégias e escolhendo a mais eficaz para aquela situação".

Alguns dos nossos alunos enfatizaram o desenvolvimento de características já citadas na pergunta um do questionário e acreditam que a metodologia de RP é uma metodologia que pode capacitar nossos estudantes a construírem seus próprios conhecimentos: "Trabalhar com a metodologia de RP foi muito bom para exercitar nossa capacidade de raciocínio e também expor nossas opiniões com o grupo", "Sim, pois aprendemos mais e nos ajudou a desenvolver várias habilidades", "A metodologia de Resolução de Problemas me agradou muito, o motivo pelo qual aconteceu isso, é que proporcionou uma aula boa para adquirir o nosso conhecimento" (grifos nossos).

Para Goi e Santos (2009), nas atividades investigativas a construção de conhecimento se dá por meio da RP que envolve etapas como observações, elaboração de questões e hipóteses, consulta a fontes de informação, planejamento e execução de planos, coleta, análise e interpretação de dados, proposição de explicações, compartilhamento de informações. Nesse sentido, os alunos se motivam e participam de forma mais efetiva das atividades de aula. Assim, compreendemos que a sequência didática implementada favoreceu aprendizagens conceituais relacionadas aos conhecimentos científicos trabalhados e, procedimentais, como a análise de referenciais bibliográficos, a confecção de relatórios e a defesa de ideias nas apresentações orais.

Ainda analisando as argumentações dos estudantes na questão três, sete alunos novamente utilizaram termos como "diferente", "inovadora", "incomum", demonstrando a pouca difusão da metodologia de ensino em questão na educação básica: "Sim... e também é uma aula diferente, foi feita a pesquisa e após a pesquisa os grupos apresentaram as resoluções dos problemas para fixar ainda mais o conteúdo", "Sim, por ser uma aula mais incomum e nova, trazendo novos conhecimentos".

\section{AlguMas CONSIDERAÇõeS}

O trabalho por nós conduzido mostrou a importância do trabalho interdisciplinar associado à metodologia de RP. Dessa maneira, de acordo com os pressupostos teóricos aqui apresentados e o trabalho feito com os educandos, sujeitos desta investigação, acreditamos que a interdisciplinaridade favorece o desenvolvimento de conhecimentos de diferentes áreas integrados a uma temática, assegurando uma maior interação entre os educandos e professores. 
Pudemos ter evidências desses resultados no decorrer das atividades realizadas, nos momentos em que os educandos, em seus grupos, discutiam as questões propostas, refletiam sobre os assuntos discutidos, ouviam opiniões divergentes, solicitavam a intervenção dos pesquisadores e, assim, chegavam às suas próprias conclusões. Cremos, dessa maneira, que esse comportamento observado leva à formação de indivíduos sociais, participativos e reflexivos. Notamos, também, que no trabalho interdisciplinar o estudante não constrói sozinho o conhecimento, mas por intermédio da ação do grupo, tendo o professor como orientador da aprendizagem. Com este viés de pensamento, consideramos que a experiência apresentada neste trabalho apresentou os princípios fundamentais de uma proposta interdisciplinar, tanto em nível das orientações dos documentos norteadores do Ensino Médio (BRASIL, 1999; 2002; 2006), quanto do referencial teórico da área (POMBO, 1994), ao integrar os objetivos entre as disciplinas de Química e Língua Portuguesa.

Da mesma maneira, percebemos que a interdisciplinaridade e a metodologia de RP estão interligadas, uma vez que também na metodologia de RP o papel do professor não é o de transmitir conhecimentos, mas de ser motivador, orientador, mediador das indagações trazidas pelos educandos. Dessa forma, o aluno não recebe pronto o conhecimento, mas o vivencia, refletindo sobre o mesmo, gerando o seu próprio conhecimento. Percebemos que a metodologia de RP é uma prática diferenciada em que há maior interação do aluno com o conteúdo, assim como entre os alunos e os professores, do que em metodologias tradicionais, favorecendo a construção do conhecimento científico contextualizado (CARVALHO; GIL-PÉREZ, 2006). Percebemos essas características, durante todo o processo vivenciado pelos pesquisadores no trabalho realizado com a turma em questão. Desde a atenção dos educandos no início do trabalho, passando pelas discussões no decorrer das resoluções até a apresentação dos problemas solucionados, sempre com muito entusiasmo e interesse por parte dos alunos.

Além disso, a pesquisa oportunizou o reconhecimento dos conteúdos conceituais, procedimentais e atitudinais, objetivo deste trabalho, nas ações dos educandos por intermédio da metodologia aplicada. Os conteúdos conceituais foram observados em momentos, por exemplo, relacionados às proposições de soluções, o que favoreceu que os novos conteúdos se relacionassem com os conhecimentos prévios dos alunos. No que diz respeito aos conteúdos procedimentais, estes foram verificados na aquisição, interpretação e análise da informação, além da organização conceitual dessa informação, durante todo o processo de nossa pesquisa, seja durante a resolução dos problemas, seja durante o debate final acerca do tema tratado. Da mesma forma, observamos os conteúdos atitudinais que se concretizaram por intermédio de 
auxílio mútuo, respeito à opinião alheia e responsabilidade na execução das tarefas solicitadas. Cabe salientar que os conteúdos apresentados não são trabalhados isoladamente, pois todos estão correlacionados à construção de um todo significativo (ZABALA, 1998).

Por fim, tendo em vista a metodologia implementada e por intermédio dos conteúdos de aprendizagem observados, notamos uma conscientização dos alunos no que tange à temática ambiental Agrotóxicos e às consequências que esses produtos químicos podem ocasionar aos seres humanos, aos animais e ao meio ambiente.

\section{REFERÊNCIAS}

ANVISA apud RIBEIRO, D. C. A. Problemas Ambientais Causados por Agrotóxicos: Uma Proposta de Formação de Professores de Química Viabilizando a Metodologia da Resolução de Problemas. 2016, 134 f. Dissertação (Mestrado em Química) - Universidade Federal do Rio Grande do Sul, Porto Alegre, 2016.

BARDIN, L. Análise de Conteúdo. Lisboa: Edições 70, 2010. 281 p.

BRASIL. Congresso Nacional. Lei Federal no 9.394. Lei de Diretrizes e Bases da Educação Nacional. Brasília, 20 de dezembro de 1996.

BRASIL. Ministério da Educação. Secretaria da Educação Média e Tecnológica. Parâmetros curriculares nacionais: ensino médio. Brasília: MEC/SEMTEC, 1999.

BRASIL. Ministério da Educação. Secretaria da Educação Média e Tecnológica. PCN+ ensino médio, Ciências da Natureza, Matemática e suas tecnologias: Orientações educacionais complementares aos parâmetros curriculares nacionais. Brasília: MEC/SEMTEC, 2002.

BRASIL. Ministério da Educação. Secretaria da Educação Básica. Orientações curriculares para o ensino médio. Volume 2. Brasília: MEC/SEB, 2006.

BRASIL. Ministério da Educação. Conselho Nacional de Educação. Resolução CEB no 02 , de 30 de janeiro de 2012. Define as Diretrizes Curriculares Nacionais para Ensino Médio.

CARDOSO, S. P; COLINVAUX, D. Explorando a Motivação para Estudar Química. Química Nova, São Paulo, v.23, n.3. p. 401-404, 2000.

CARVALHO, A.M.P.; GIL-PÉREZ, D. Formação de Professores de Ciências: tendências e inovações. São Paulo: Cortez, 2006. 120p.

CURY, A. J. Pais brilhantes, professores fascinantes. Rio de Janeiro: Sextante, 2003.

ECHEVERRÍA, M. P. P. e POZO, J. I. Aprender a resolver problemas e resolver problemas para aprender. Em: POZO, J. I. (Ed.). A solução de problemas: aprender a resolver, resolver para aprender (p. 13-42). Porto Alegre: Artmed. 1998.

GÓI, M. E. J.; SANTOS, F. M. T. Resolução de problemas e atividades práticas de laboratório: uma articulação possível. In: ENCONTRO NACIONAL DE PESQUISA EM EDUCAÇÃ̃ EM CIÊNCIAS, 5., 2005, São Paulo. Atas... São Paulo: Bauru, 2005. 
LIPMAN, M. O Pensar na Educação. Petrópolis: Vozes, 1995.

LÜDKE, M.; ANDRÉ, M. Pesquisa em Educação: Abordagens qualitativas. São Paulo: EPU, 1986.

NERY, A. L. P.; LIEGEL, R. M.; FERNANDEZ, C. Reações envolvendo íons em solução aquosa: uma abordagem problematizadora para a previsão e equacionamento de alguns tipos de reações inorgânicas. Química Nova na Escola, v. 23, p. 14-18, 2006.

POMBO, O. A interdisciplinaridade: conceito, problemas e perspectivas. In: POMBO, O.; LEVY, T.; GUIMARÃES, H. (org). A interdisciplinaridade: reflexão e experiência. Lisboa: Texto, 1994.

PORLÁN A. R.; MARTÍN, J. El diario del profesor: Un recurso para la investigación en el aula. 6 ed. Sevilla: Díada, 1998.

POZO, J. I.; CRESPO, M. Á. G. A solução de problemas em ciências da natureza. In: POZO, J. I. (org.) A solução de problemas. Porto Alegre: Artmed, 1998. p. 67-102.

RIBEIRO, D. C. A. et al. A metodologia da resolução de problemas: uma proposta para abordagem sobre agrotóxicos no ensino médio. In: I ENCONTRO REGIONAL DE ENSINO DE CIÊNNCIAS, 2017, 1, Santa Maria. Anais... Santa Maria: UFSM, 2017a. p 79-84.

RIBEIRO, D. C. A. et al. A Temática Ambiental Agrotóxicos: A Metodologia da Resolução de Problemas na Educação de Jovens e Adultos. XI ENCONTRO NACIONAL DE PESQUISA EM EDUCAÇÃO EM CIÊNCIAS, 11, 2017, Florianópolis. Atas... Florianópolis: UFSC, 2017b. p. 1-9.

RIBEIRO, D. C. A. et al. A metodologia da resolução de problemas: abordando a temática agrotóxicos no ensino fundamental. In: SIPEQ - V SEMINÁRIO INTERNACIONAL DE PESQUISAS QUALITATIVAS, 5, 2018, Foz do Iguaçu, Atas... Foz do Iguaço: Unioeste, 2018a. p. 1-12.

RIBEIRO, D. C. A. et al. (aceito). A metodologia da resolução de problemas: uma proposta interdisciplinar sobre agrotóxicos na educação de jovens e adultos. Revista Linhas. (2018b).

SANTOS, W. L. P.; MÓL, G. S. (org). Projeto de Ensino de Química e Sociedade: Química cidadã. 2 ed. São Paulo: AJS. 2013.

SCRIVANO, C. N. et al. Ciências, transformação e cotidiano: Ciências da natureza e matemática ensino médio: Educação de Jovens e Adultos. 1 ed. São Paulo: Global, 2013.

SOARES, M. T. C.; PINTO, N. B. Metodologia da Resolução de Problemas. $33^{a}$ reunião Anual da Anped, GT 19. 2001.

YIN, R. K. Estudo de caso: planejamento e métodos. $2^{\text {a }}$ Ed. Porto Alegre. Editora: Bookmam. 2001.

ZABALA, A. A prática educativa: como ensinar. 1 ed. Porto Alegre: Artmed, 1998. 224p.

Recebido em: 28 de setembro de 2018 .

Aprovado em: 26 de novembro de 2018. 